\title{
UMA ANÁLISE DO PROCESSO PARTICIPATIVO PARA A CONSERVAÇÃO DO AMBIENTE NA CRIAÇÃO DA RESERVA EXTRATIVISTA ACAÚ-GOIANA
}

\section{An analysis of participative practices to the environmental conservancy in the creations of Reserva Extractivista Acaú-Goiana}

\author{
Amanda Braga de Melo Fadigas \\ Mestre em Desenvolvimento e Meio Ambiente pelo Programa de Pós-Graduação em Desenvolvimento e Meio Ambien- \\ te da Universidade Federal da Paraíba. \\ João Pessoa/Paraíba - Brasil \\ amanda01dir@gmail.com \\ Loreley Gomes Garcia \\ Professora do Programa de Pós-Graduação em Desenvolvimento e Meio Ambiente e do Programa de Pós-Graduação \\ em Sociologia ambos da Universidade Federal da Paraíba. \\ João Pessoa/Paraíba - Brasil \\ loreleygg@gmail.com
}

Artigo recebido para publicação em 16/03/2010 e aceito para publicação em 09/11/2010

RESUMO: $\quad$ A ampliação dos espaços democráticos no Brasil tem viabilizado a gestão compartilhada dos recursos naturais por meio dos processos participativos. As Unidades de Conservação, desde o início dos anos 90, vêm experimentando inserir esta perspectiva em suas diversas categorias, principalmente no caso das reservas extrativistas, que trazem a participação como um princípio essencial de sua existência. Esse contexto impulsiona o surgimento de novos atores sociais e reivindicações mais complexas, como se vê no histórico de luta das mulheres, grupo social por vezes à margem dos processos decisórios. As mulheres têm assumido um papel diferenciado, pautando novos espaços equitativos que ampliem o debate sobre a sustentabilidade dos processos ecológicos essenciais para a sua subsistência. Neste sentido, este artigo analisa práticas participativas exercidas por marisqueiras nos espaços decisórios fomentados pelo processo de criação da Reserva Extrativista Acaú-Goiana e suas contribuições para o fortalecimento da cidadania exercida em prol da conservação do ambiente.

Palavras-chave: Processos participativos. Reserva extrativista. Marisqueiras.

\begin{abstract}
The expansion of Brazilian democratic spaces has enabled shared management of natural resources through participatory processes. The Conservation Units, since the beginning of the 90s, have endeavored to insert this perspective in theirs various categories, chiefly in the case of extractive reserves, a category that holds participation as an essential principle of its existence. This context enables the emergence of new social players and more complex claims, as can be seen from the history of women's struggle, a social group often marginalized from decision-making process. Women have assumed a differentiated role, determining new equitable spaces that expand discussions on the sustainability of ecological processes essential for their subsistence. In this aspect, this paper analyses participative practices exercised by women shellish collectors in deciding spaces promoted by the creation process of Reserva Extrativista Acau-Goiana and its contributions to reinforce the citizenship exercised in favor of the environmental conservation.
\end{abstract}

Keywords: Participative process. Extractive reserve. Women shellfish collectors. 


\section{INTRODUÇÃO}

A ampliação dos espaços democráticos no Brasil tem viabilizado a gestão compartilhada dos recursos naturais, por meio dos processos participativos. Esse paradigma, que se iniciou há pouco mais de duas décadas, tem revelado a sociedade civil e suas entidades como novas gestoras ambientais competentes para atuar em prol do equilíbrio dos sistemas naturais (BAQUEIRO, 2001; DAGNINO, 2004).

Dentre os instrumentos de gestão dos recursos naturais adotados pela Política Nacional do Meio Ambiente, as Unidades de Conservação (UC) têm se destacado pela inserção dos processos participativos em suas etapas de criação, implantação e gestão, principalmente no caso das reservas extrativistas (resex), categoria que tem a participação como um princípio essencial. Esta peculiaridade se concretiza na própria história das reservas extrativistas, pois são fruto de um intenso processo participativo de origem popular que foi peça-chave para inserir na política ambiental brasileira a vertente social.

O surgimento das primeiras reservas extrativistas tem sua origem no Acre, no final da década de 1970. Liderados por Chico Mendes, os povos da floresta, especialmente os seringueiros, protagonizaram uma extensa pauta de reivindicações, com pontos que iam desde a autonomia frente aos fazendeiros à conservação do ambiente relacionado ao exercício de suas atividades (ALEXANDRE, 2002; ANTUNES, 2005; DIEGUES 2000; SANTILLI, 2005).

Para compreender de forma geral as etapas que consolidam uma reserva extrativista, visualizemos o Quadro 1:
Em um primeiro plano é necessário considerar que a fase da 'criação' se caracteriza pelo conceito da legitimidade, uma vez que a resex é demandada ao Poder Público exclusivamente pela população extrativista frente a uma ameaça ao equilíbrio socioambiental. O objetivo prioritário da demanda é garantir a sociobiodiversidade e a reprodução do modo de vida destes grupos.

A organização social da comunidade é um requisito fundamental, já que dessa maneira irão sustentar suas reivindicações nos espaços decisórios. Assim, cabe à comunidade realizar uma solicitação formal para a criação da reserva. Não há na legislação uma interpretação restritiva para o formato que deve ser adotado por esta solicitação, na prática o mais recorrente são os abaixo-assinados. Compete ao órgão ambiental recepcionar a demanda e seguir com os trâmites administrativos.

Para o Poder Público, representado pelo órgão ambiental, o princípio está no estudo técnico que analisa a viabilidade para criar esta categoria de UC, o que é feito através de um diagnóstico dos aspectos relevantes da área e da comunidade e da realização de reuniões comunitárias. Caso o estudo técnico obtenha um resultado favorável, se oficializa o processo administrativo de criação da reserva extrativista.

Por fim, o órgão ambiental deve cumprir a exigência legal de escutar exaustivamente a população e demais atores interessados por meio de reuniões e Consultas Públicas, a fim de que se esgotem todas as dúvidas e se concretize a proposta da comunidade. Essas Consultas Públicas, por serem espaços públicos decisórios, devem garantir minimamente dois

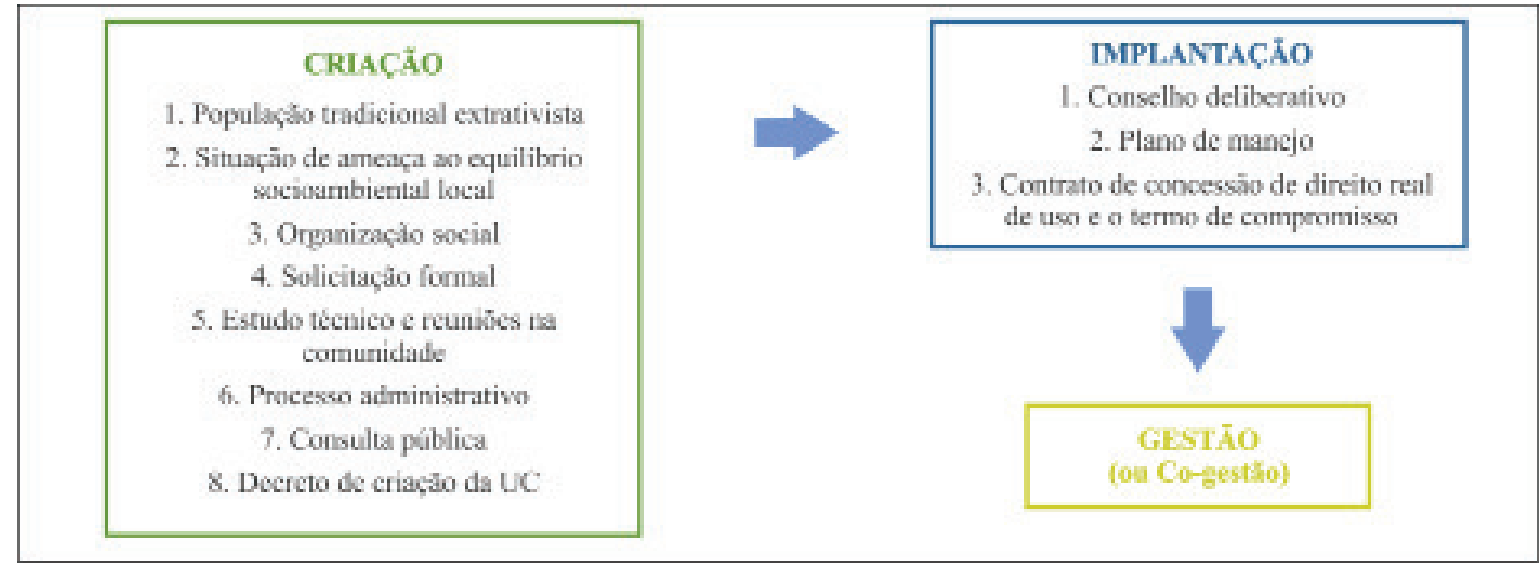

Quadro 1: Etapas para o surgimento de uma Reserva Extrativista conforme dispositivos legais.

Fonte: Pesquisa direta. Abril, 2008

Sociedade \& Natureza, Uberlândia, 22 (3): 561-576, dez. 2010 
princípios: o da participação e o da informação. Este é o momento em que a população terá oportunidade de expor suas pretensões, conhecer os argumentos técnicos e dialogar com outros interessados, como as organizações não governamentais e o setor produtivo. As informações veiculadas durante as Consultas devem ser claras, inteligíveis e idôneas, de modo que todos tenham a oportunidade de tomar suas decisões.

A última fase para criação da resex fica a cargo do Poder Executivo, quando através de um decreto oficializa a existência jurídica da reserva extrativista, reconhecendo a demanda legítima da população extrativista.

Inseridas neste contexto de meio ambiente e participação, as marisqueiras da divisa litorânea da Paraíba (PB) e de Pernambuco (PE) iniciaram em 1999 discussões sobre a necessidade de proteger a área estuarina onde realizam a coleta de um molusco bivalve, conhecido na região por marisco, anomalocardia brasiliana (Gmelin, 1791) (mollusca, bivalvia, veneridae).

Os bancos de marisco se encontram no estuário dos rios Goiana e Megaó, ecossistema que possui uma relevância vital para a preservação da cultura local da pesca, incluindo a catação de marisco, atividade caracteristicamente desempenhada pelas mulheres.

Através do exercício diário de suas atividades laborais, as marisqueiras constroem um rico conhecimento local sobre a dinâmica do ecossistema estuarino, bem como observa e avalia os impactos sofridos pela área (DI CIOMMO, 2007; STADTLER, CARNEIRO, 2006). O resultado dessas percepções foi levado ao Instituto Brasileiro do Meio Ambiente e dos Recursos Naturais Renováveis (IBAMA) por meio destas atrizes sociais, receosas de que as atividades econômicas desenvolvidas na área pudessem inviabilizar o equilíbrio do ecossistema estuarino. Após a instauração e cumprimento do processo administrativo, em 26 de setembro de 2007 foi criada através de Decreto Federal a Reserva Extrativista Acaú-Goiana.

Portanto, este estudo pretende analisar o processo participativo de criação da Reserva Extrativista Acaú-Goiana e em seu conteúdo identificar elementos que possam contribuir com a consolidação dos espaços decisórios participativos e com o fortalecimento da cidadania exercida pelas marisqueiras em prol da conservação do ambiente.

\section{O HISTÓRICO DO PROCESSO DE CRIAÇÃO DA RESERVA EXTRATIVISTA ACAÚ-GOIANA}

Entre os anos de 1998 e 1999 a região que se estendia desde o Canal de Santa Cruz, em Pernambuco, até o estuário dos rios Goiana e Megaó, na divisa da Paraíba com Pernambuco, vivia um período marcado pelos graves danos socioambientais provocados por uma intensa atividade econômica que atuava há décadas naquela área em desconformidade com a legislação ambiental.

As primeiras propostas para sanar os problemas socioambientais daquela zona pesqueira se estruturaram de modo fragmentado. As lideranças comunitárias do litoral norte pernambucano, em parceria com o Conselho Pastoral dos Pescadores (CPP) discutiram em 1998 sobre a proteção da área do Canal de Santa Cruz, que devido a sua riqueza ecossistêmica é considerado o mais importante pólo pesqueiro de Pernambuco. Contudo, esta alternativa não englobava o diálogo com as comunidades da Paraíba e ainda dividia o estuário dos rios Goiana e Megaó pela metade. Entretanto este debate não prosseguiu.

Por sua vez, o distrito de Acaú, pertencente ao município de Pitimbú, no litoral sul da Paraíba, foi atingido gravemente em 1999 pelo impacto ambiental das atividades industriais, agrícolas e da carcinicultura. As marisqueiras foram as primeiras a notar a degradação, ao ver um ciclo de escassez do marisco sem precedentes. Neste mesmo ano a Associação das Marisqueiras de Acaú sustentou a idéia do defeso do marisco, na tentativa de preservar a fauna estuarina e a manutenção das famílias que viviam exclusivamente da pesca artesanal. A necessidade de conservação cresceu, e a associação promoveu um abaixo-assinado solicitando ao IBAMA a proteção do estuário dos rios Goiana e Megaó. O processo administrativo foi então instaurado em 2001, encaixando a proteção da área nos termos de Reserva Extrativista. No entanto, esta proposta também dividia o ecossistema estuarino, pois utilizava como parâmetro os limites geopolíticos entre os estados da Paraíba e de Pernambuco. Devido a diversas lacunas o processo foi arquivado ainda em 2001. 
O processo ressurge em 2002 quando o IBAMA retoma contato com as lideranças comunitárias, resgatando a demanda de Acaú e abrindo o diálogo para todas as comunidades diretamente relacionadas com o estuário. O encontro de idéias e lutas entre as lideranças da Paraíba e de Pernambuco ganha o reforço de um abaixo-assinado organizado pela comunidade pesqueira de Pernambuco, apoiada pelo Conselho Pastoral dos Pescadores, que facilitava o intercâmbio de experiências sociais naquela área.

Os trâmites avançam na direção de inserir novos parceiros. No ano de 2004 os técnicos da

\section{IDENTIFICANDO GRUPOS E ATORES EN- VOLVIDOS NA CRIAÇÃO DA RESEX ACAÚ- GOIANA}

Diversos órgãos e entidades associativas se envolveram direta e indiretamente na criação da Resex Acaú-Goiana, contudo houve aqueles que se destacaram pela participação ativa, contribuindo em cada etapa do processo até o êxito da Resex. Podemos classificar estes atores entre o Setor Público Estatal e o Setor Público não-Estatal, conforme apresenta o Quadro 2 abaixo:

\begin{tabular}{|c|c|}
\hline Setor Público Estatal & Setor Público não-Estatal \\
\hline $\begin{array}{l}\text { - Centro Nacional de Populações Tradicionais (CNPT) } \\
\text { O Comissão de Meio Ambiente da Assembléia Legislativa de } \\
\text { Pernambuco } \\
\text { o Fundação Joaquim Nabuco } \\
\text { o IBAMA da Paraíba } \\
\text { O IBAMA de Pernambuco } \\
\text { - Prefeitura de Caaporã } \\
\text { - Prefeitura de Goiana } \\
\text { - Prefeitura de Pitimbú } \\
\text { O Universidade Federal da Paraíba }\end{array}$ & $\begin{array}{ll}\circ & \text { Associação das Marisqueiras de Acaú (PB) } \\
\circ & \text { Associação de Moradores da Pontinha (PB) } \\
\circ & \text { Associação de Moradores de Carne de Vaca (PE) } \\
\circ & \text { Associação de Pesca e Aqüicultura de Caaporã (PB) } \\
\circ & \text { Centro Josué de Castro } \\
\circ & \text { Colônia de Pescadores de Acaú (PB) } \\
\circ & \text { Colônia de Pescadores de Atapuz (PE) } \\
\circ & \text { Colônia de Pescadores do Baldo do Rio (PE) } \\
\circ & \text { Colônia de Pescadores de Ponta de Pedras } \\
\circ & \text { Colônia de Pescadores de Tejucupapo (PE) } \\
\circ & \text { Conselho Pastoral dos Pescadores }\end{array}$ \\
\hline
\end{tabular}

Quadro 2: Descrição dos órgãos e entidades associativas envolvidas na criação da Resex Acaú-Goiana.

Fonte: Pesquisa direta. Abril, 2008

Universidade Federal da Paraíba (UFPB) firmam parceria com o IBAMA/PB para emitir um parecer prévio sobre o caso. A decisão dos técnicos aponta a necessidade de integrar toda a área do estuário na Resex, assim as comunidades de Carne de Vaca, Povoação de São Lourenço, Ponta de Pedras, Baldo do Rio, Tejucupapo e Atapuz, todas localizadas no litoral norte de Pernambuco, foram oficialmente convidadas às reuniões que deram forma aos espaços decisórios participativos.

No período que corresponde aos anos de 2004 a 2007, o processo de criação da Reserva Extrativista Acaú-Goiana tomou forma com o princípio de um novo diagnóstico sócio-econômico, biológico e ambiental da área e com a realização de diversas reuniões e consultas nas comunidades, permitindo assim verificar as práticas participativas, dentre outros aspectos relevantes para a implantação e futura gestão da resex.
Dentre as entidades do Setor Público não-Estatal observamos em um plano especial a atuação das entidades locais, como a Associação das Marisqueiras de Acaú (PB), a Colônia de Pescadores de Ponta de Pedras e a Colônia de Pescadores do Baldo do Rio.

A Associação das Marisqueiras atuou persistentemente desde 1999 levando a proposta de proteção da área ao IBAMA/PB. Único grupo constituído somente por marisqueiras, a associação foi precursora na defesa dos interesses específicos das pescadoras de Acaú.

A Colônia de Pescadores de Ponta de Pedras esteve envolvida na proposta da Resex Acaú-Goiana desde 2002. A atuação desta colônia foi essencial para assegurar a participação das comunidades pernambucanas no processo de criação da Resex, uma vez que também representava as comunidades de Carne de Vaca e São Lourenço. Esta colônia se caracteriza ainda por possuir larga experiência em processos participativos, além do vasto conhecimento sobre a área do estuário. 
Por sua vez, a Colônia de Pescadores do Baldo do Rio esteve desativada até o ano de 2004. Quando reestruturada entrou no processo de criação da Resex estabelecendo uma importante parceria com a Colônia de Ponta de Pedras. A partir de então se fortaleceu a representatividade dos pescadores e pescadoras do litoral norte de Pernambuco.

Outra grande colaboração à Resex foi trazida pelo Conselho Pastoral dos Pescadores. Este parceiro das comunidades pesqueiras da Paraíba e Pernambuco atuou como entidade mobilizadora, incentivadora e fiscalizadora durante todas as fases do processo de criação da Resex.

Por fim, merece destaque toda a comunidade de pescadoras e pescadores da Paraíba e de Pernambuco, bem como de suas lideranças, constituídas principalmente por mulheres ativistas naquela região.

\section{A AMEAÇA AO EQUILÍBRIO DO ESTUÁRIO DOS RIOS GOIANA E MEGAÓ}

De acordo com as entrevistas semi-abertas realizadas em campo com as marisqueiras de Acaú e Carne de Vaca em maio de 2008, os principais danos socioambientais sofridos pela área estuarina dos rios Goiana e Megaó foram provocados predominantemente pela realização das atividades econômicas da agricultura (canaviais), da indústria e da carcinicultura (FADIGAS; GARCIA; HERNANDEZ, 2008).

Ao intensificar o plantio da cana-de-açúcar na costa litorânea dos Estados da Paraíba e de Pernambuco, uma das principais zonas atingidas foi o estuário dos rios Goiana e Megaó e conseqüentemente suas comunidades pesqueiras, como Acaú (PB) e Carne de Vaca (PE). O cultivo da cana substituiu a mata ciliar, invadindo a beira dos rios e áreas de mangue. A monocultura provocou ainda um desmatamento desenfreado na região em que antes predominava a Mata Atlântica. Os resíduos do cultivo eram descartados sem tratamento adequado na zona estuarina. Como conseqüência houve uma alteração significativa no equilíbrio do microclima, além da mudança na economia local, pois a área se tornou valorizada para outros setores da economia elevando o preço de mercadorias e imóveis, que raramente estavam sob a propriedade dos moradores comunitários.
A atividade industrial, por sua vez, alterou de modo expressivo a paisagem local. Indústrias como a de cimento e destilarias compraram ou arrendaram terras e instalaram suas sedes principalmente à margem paraibana do estuário. A este processo de ocupação massiva da área, que não prescindiu do desmatamento, se soma o despejo dos resíduos industriais in natura na área do estuário.

Para rematar, acrescentamos as conseqüências geradas pela atividade da carcinicultura. No final da década de 1990 o maior viveiro de camarão ativo na zona de influência do estuário dos rios Goiana e Megaó, localizado na Ilha de Tiriri (PE), provocou uma grande mortandade de recursos pesqueiros com o despejo sem tratamento de suas águas residuais provenientes dos tanques de criação, atingindo assim toda a pesca estuarina do litoral norte de Pernambuco e do litoral sul da Paraíba.

Outras causas que foram identificadas se referem a fatores migratórios e à sobrepesca do marisco. Nas duas últimas décadas houve uma significativa migração de pessoas provenientes de Recife, Goiana, João Pessoa, Caaporã e demais cidades dos arredores, provocando uma pressão sobre os poucos recursos pesqueiros que resistiram à deterioração da área. Ao especificar a pesca do marisco, verificamos que este recurso tem resistido à degradação ambiental, contudo já se encontra em uma fase de declínio, tanto pela escassez quanto pelo tamanho reduzido da espécie em idade adulta.

As mudanças ocorridas nesta área do estuário dos rios Goiana e Megaó atingiram toda a comunidade pesqueira, especialmente as marisqueiras de Acaú (PB) e Carne de Vaca (PE), uma vez que a coleta do marisco tem um papel importante na manutenção da economia familiar local (DIAS, ROSA, DAMASCENO, 2007; FADIGAS, GARCIA, 2008).

Para estas pescadoras, como decorrência da escassez dos recursos pesqueiros, está a necessidade de pescar em áreas cada vez mais distantes das margens dos rios, solicitando assim mais tempo e outros equipamentos de pesca de alto custo para aquela realidade social, como o barco.

Todo este contexto, que usurpava o modo de vista extrativista destas comunidades pesqueiras estuarinas, levou as marisqueiras a refletir sobre a 
possibilidade de pleitear o defeso do marisco, tal como está regulamentado o defeso da lagosta. Ainda que de modo incipiente e precário, no que se refere ao apoio de outras instituições, as marisqueiras de Acaú, fortalecidas com suas representantes, iniciaram as primeiras discussões em 1999 sobre a proteção da área estuarina e apenas em 2004, unidas com as lideranças pesqueiras de Pernambuco, levaram a cabo a demanda para a criação da Reserva Extrativista Acaú-Goiana.

\section{O REQUISITO LEGAL DA SOLICITAÇÃO FORMAL}

Para instaurar um processo administrativo de criação de Resex a Instrução Normativa ${ }^{\circ} 03$ de 2007 do Instituto Chico Mendes de Conservação da Biodiversidade (ICMBio) designa que a população extrativista solicite formalmente a proteção da sua área, reforçando o caráter de legitimidade desta UC. No caso estudado, as comunidades pesqueiras procederam com a realização de um abaixo-assinado, modalidade de solicitação comumente utilizada.

Como foi citado anteriormente, em Acaú surgiu o primeiro manifesto que iniciou as discussões. $\mathrm{Na}$ época, a Associação das Marisqueiras de Acaú elaborou o documento relatando a preocupação da comunidade sobre a devastação do mangue e dos bancos de marisco que mantinham a subsistência das famílias locais.

As assinaturas foram recolhidas entre os comunitários que entenderam a importância da demanda, contudo não tinham pleno conhecimento do que significaria proteger a área com a definição de novos limites geográficos; conceitos como 'meio ambiente' e 'reserva extrativista' ainda eram abstrações que só constituíam o universo técnico-acadêmico.

Por sua vez, os abaixo-assinados das comunidades de Pernambuco surgiram mais tarde e com outro caráter. O CPP foi o elemento diferenciador, por realizar um trabalho de base com aquelas comunidades estimulou os grupos locais a experimentar uma mudança de comportamento e pensamento frente aos problemas socioambientais que vinham atingindo aquela área estuarina.

Dada a unificação das intenções de ambas as comunidades pela proteção da área, se concretizou uma verdadeira tomada de decisão por parte das pescadoras e dos pescadores. É importante destacar que uma solicitação apenas se fortalece na medida em que encontra legitimidade na participação dos atores sociais, caso que se confirmou na Resex Acaú-Goiana.

\section{O PARECER TÉCNICO}

De acordo com os artigos $6^{\circ}$ e $7^{\circ}$ da Instrução Normativa $n^{\circ} 03$ de 2007 do ICMBio, é de sua competência a emissão do parecer técnico atestando a viabilidade para a criação da Resex e propondo seus limites. Esta fase está prevista pelo artigo $4^{\circ}$ do Decreto $n^{\circ} 4340$ de 2002, que regulamenta a Lei 9.985 de 2000, que institui o Sistema Nacional de Unidades de Conservação. No entanto, o parecer deve estar fundamentado em estudos que se baseiem na vistoria da área e nas reuniões com a comunidade. A partir da emissão deste parecer o processo administrativo de criação da Resex é formalizado.

Os estudos sobre a área de influência do estuário dos rios Goiana e Megaó foram sistematizados em um diagnóstico socioeconômico, ambiental e biológico, elaborado por técnicos da Universidade Federal da Paraíba e concluído no ano de 2006.

Ao caracterizar a comunidade pesqueira, o estudo evidencia que as marisqueiras são essencialmente dependentes da área do estuário dos rios Goiana e Megaó, conforme foi registrado em Acaú, São Lourenço, Carne de Vaca e Tejucupapo. A maioria dos questionados pela equipe técnica afirmou que a mariscagem, associada à catação de outros moluscos e/ou crustáceos, corresponde à principal atividade econômica local.

Apesar da importância da mariscagem naquela região, o estudo não abordou alguns temas transversais que poderiam contribuir tanto para a criação quanto para a gestão da Resex, como a divisão sexual do trabalho, a participação no associativismo e nos espaços públicos e os principais problemas enfrentados pelas marisqueiras ao exercer sua profissão. Esses aspectos tão presentes no contexto pesqueiro (AGUILAR, CASTAÑEDA, 2000; DI CIOMMO, 2007; SIMONIAN, 2006; STADLER, CARNEIRO, 2006.) se refletem na realidade das comunidades estudadas, que demonstraram um forte descrédito em relação à 
atualidade da pesca artesanal.

No quesito ambiental, o diagnóstico se restringe a pontuar os impactos ambientais da área; dentre eles o acúmulo de lixo, o lançamento de esgoto doméstico, a retirada de mata ciliar em áreas urbanas, o desmatamento, a ocupação desordenada, a pesca predatória e a carcinicultura. Somam-se a esses fatores a indústria do turismo, a especulação imobiliária, e o avanço da economia açucareira. Contudo o diagnóstico não traça uma análise complexa interrelacionando as atividades econômicas que predominam na região - agricultura, indústria e carcinicultura - com os principais danos socioambientais sofridos naquela área, conforme indica a comunidade pesqueira (FADIGAS; GARCIA; HERNANDEZ, 2008).

Em termos gerais, o estudo técnico se limitou a solicitar da população que identificasse "qual é o conflito", sem apontar os danos provocados e suas conseqüências. Deve ser ainda considerado que o estudo, ao enfocar apenas o conflito mais grave, acaba omitindo as demais atividades que provocaram e seguem gerando danos graves à área, ou seja, se perde o histórico desses danos e como isso corroborou com a sobrepesca local.

Em uma segunda etapa foram realizadas reuniões comunitárias com o objetivo de apresentar à população pesqueira os resultados do estudo técnico. Além de apresentar os dados levantados, as reuniões tinham a obrigação legal de atender as dúvidas da população sobre a criação, implantação e gestão da resex.

As reuniões seguiram um roteiro padronizado que sofria alterações de acordo com a especificidade de cada localidade. Pontuamos:

1. Narração do histórico de aproximação do ICMBio/IBAMA com as comunidades e da discussão sobre a criação da Resex;

2. Apresentação do diagnóstico sócio-econômico, biológico e ambiental;

3. Discussão sobre os limites geográficos da área da Resex;

4. Espaço para dirimir dúvidas e ratificar a solicitação de criação da Resex.

Ainda que realizadas em diferentes comunidades, as observações das marisqueiras e pescadores convergiram entre si, sendo sistematizados os principais pontos, a seguir:
- A efetividade do defeso, e a extensão do benefício ao marisco;

- O questionamento dos limites geográficos propostos para a Resex, pois temiam que a área não contemplasse os principais locais de pesca;

- Denúncias de degradação ambiental provocadas por grandes atividades econômicas;

- A rivalidade interna entre as comunidades pesqueiras, o que gera desconforto e dúvidas para a comunidade pesqueira;

- A inclusão de toda a área de mangue nos limites da Resex. As comunidades afirmaram com segurança a importância do mangue e de sua preservação;

- O papel que deve exercer a Colônia dos Pescadores, principalmente em relação à divulgação dos direitos e deveres dos pescadores;

Após delimitar os principais aspectos desta fase do processo é mister pontuar fatores que podem auxiliar futuros processos de criação de Resex. Preliminarmente podemos considerar que as reuniões garantiram certa diversidade quanto aos grupos que participaram dos debates, embora não tenha sido identificada uma presença significativa de membros do setor produtivo local, atores que devem estar envolvidos na discussão. Contemplaram as reuniões líderes comunitários, representantes governamentais (das três esferas) e representantes da comunidade pesqueira, marisqueiras em sua grande maioria.

A hierarquia existente entre técnicos e comunitários foi evidente. O formato 'mesa e platéia' é o primeiro indicador de que há um afastamento entre os dois grupos, o que não favorece processos participativos. O discurso adotado pelos técnicos também é uma chave para o êxito das reuniões, no caso analisado ora se aproximava de uma 'leitura' de cartilhas ou manuais técnicos (sem considerar a troca de conhecimento), ora imputava a culpa pela degradação da área apenas aos comunitários.

Todos estes fatores refletiram no aspecto quanti-qualitativo da participação popular no debate. Foram raras as interferências da comunidade, geral- 
mente cercadas de dúvidas voltadas aos direitos trabalhistas, aos costumes da pesca e ainda a denúncias e/ou indignações que não eram contestadas, deixando um verdadeiro espaço em branco.

As reuniões expuseram ainda dois conflitos remotos e pendentes: comunidade versus comunidade, comunidade versus IBAMA. O primeiro caso revela a rivalidade na pesca de algumas comunidades, afirmando que a população tradicional de pescadores não é homogênea, cada grupo é movido por seu próprio interesse. Esses conflitos locais não foram apontados pelo diagnóstico da área e quando apresentados nas reuniões permaneceram sem uma medida de mediação prevista.

Em relação ao binômio comunidade versus IBAMA, o que foi encontrado na área não destoa do histórico das populações tradicionais. Alguns autores (GARCIA, 1999; PRADO, 2000; ALEXANDRE, 2002;) descrevem sobre os problemas enfrentados nas áreas protegidas quando enfocada esta temática, como demonstra o estudo realizado por Garcia (1999) sobre a Reserva Extrativista de Pirajubaé. De fato não há uma relação de total insegurança ou descrédito com o órgão, porém se sobressai a insatisfação quanto à política ambiental que vem sendo adotada nas últimas décadas pela autarquia. As principais inquietudes se referem à conduta repressora do órgão.

Como fator relevante das reuniões, se destaca a atuação das pescadoras. Com uma representação forte nas reuniões, as mulheres tiveram uma participação bastante significativa nos debates, principalmente por meio das lideranças.

Essas lideranças comunitárias representavam majoritariamente a Associação das Marisqueiras de Acaú, a Colônia de Pescadores Z3 de Ponta de Pedras (abrangendo São Lourenço e Carne de Vaca), a Colônia de Pescadores Z14 de Baldo do Rio, além de organizações não governamentais locais.

As intervenções destas pescadoras-lideranças podem ser categorizadas em três vias:

1. Conhecimento dos principais problemas sócio-ambientais locais;

2. Compreensão da teia de fatores que afetam a transformação do ambiente;

3. Formas de atuação em defesa do ambiente
Sobre o primeiro ponto destacado, as lideranças locais puderam especificar cada problema enfrentado na área em anos anteriores a partir da percepção constante da rotina de suas comunidades. Em relação ao segundo tópico, as lideranças possuíam um entendimento crítico e complexo sobre como fatores sociais, econômicos e políticos interferiram na qualidade ambiental do estuário. Por fim, as lideranças evidenciaram seu papel institucional, engajadas na defesa dos interesses da sua categoria, e cobrando aos órgãos competentes as devidas ações para o bom funcionamento da pesca artesanal.

Além destas observações sobre a atuação das lideranças, adicionamos o caráter de envolver a comunidade no processo e a preocupação em informá-la sobre os direitos e deveres vinculados à resex.

\section{AS CONSULTAS PÚBLICAS}

As Consultas Públicas constituem um procedimento que atende a vários tipos de oitiva de interessados, e não é presidida necessariamente por membro do Ministério Público, como no caso da Audiência Pública. Para as reservas extrativistas, a escuta dos seus interessados se estabelece como um requisito obrigatório que solidifica o processo participativo dessa categoria de UC.

Após quase um ano da realização das reuniões comunitárias, o IBAMA designou o cumprimento das Consultas Públicas. Assim, em Março de 2006, foram realizadas as Consultas Públicas em Acaú (PB) e Goiana (PE) para consolidar a proposta da Resex, tendo em vista também a definição dos seus limites geográficos e a eleição do nome da mesma.

As consultas foram presididas por membros do CNPT/Brasília que iniciou os trabalhos com uma breve explanação acerca da Resex considerando seu histórico e características. Em seguida, o espaço foi direcionado aos pronunciamentos dos presentes para ao final levar à votação o nome da resex como também delimitar a área da UC.

No entanto cada consulta se definiu em função dos fatores locais, como pode ser verificado em seguida: local. 


\section{CONSULTA PÚBLICA EM ACAÚ/PB}

No distrito de Acaú a consulta foi realizada no prédio da Igreja Católica, que por seu tamanho reduzido não proporcionou a todos a mesma oportunidade de usufruir da reunião. Muitos comunitários se acomodaram na área exterior e tiveram acesso à Consulta por meio de um telão, que transmitiu o debate apenas por meio de imagens, já que houve falha técnica na transmissão do áudio. Somado a isso, se constatou que algumas pessoas presentes acreditavam estar em uma reunião da colônia de pescadores para discutir sobre o último defeso. Ao serem informados do real conteúdo da reunião houve o desinteresse de muitos destes em continuar no local.

Mesmo com os transtornos e imprevistos ocasionados, foram muitos os presentes. Além dos comunitários - pescadoras em sua maioria - compareceram representantes do poder municipal de Pitimbú, notadamente o Presidente da Câmara dos Vereadores; a Associação das Marisqueiras de Acaú; a Colônia de Pescadores Z10 de Acaú; representantes do Governo do Estado da Paraíba; IBAMA/PB e PE; UFPB, CNPT e do CPP.

As representantes das marisqueiras lideraram as intervenções comunitárias, que frisaram a situação de desequilíbrio ambiental da área e sua relação com o setor sucroalcooleiro e da carcinicultura. Por outro lado, a platéia de comunitários demonstrou sua dificuldade em se manifestar, algo já identificado pelas próprias lideranças. $\mathrm{O}$ medo é o grande entrave no diálogo, pois diversos são os relatos de pescadores e marisqueiras que sofreram algum tipo de retaliação ou ameaça indevida ao exercer seu ofício.

Nesta consulta as comunidades começaram a definir possíveis alianças para a futura gestão da Resex. Um claro exemplo surgiu da postura assumida pelo poder legislativo local, através da Câmara Municipal de Vereadores de Pitimbú. Mesmo tendo declarado oficialmente apoio à Resex, a Câmara retirou a adesão à proposta após ser informada de que as atividades econômicas incidentes nos limites da Resex estariam condicionadas à nova regulamentação e que sofreriam punição caso estivessem em discordância com a legislação vigente. As alianças mais concretas em prol da Resex ficaram de fato assentadas entre as próprias comunidades, embora existam diferenças entre estes grupos.

\section{Consulta Publica em Goiana/PB}

A consulta no município de Goiana se realizou em um prédio amplo cedido pelo poder legislativo local, que apesar das dimensões não foi suficiente para albergar os diversos pescadores e pescadoras presentes. A transmissão de áudio àqueles que se encontravam fora do prédio também passou por problemas, gerando a insatisfação da comunidade pesqueira.

Os grupos comunitários - desta vez com a presença marcante dos pescadores, apesar de haverem algumas marisqueiras - estavam unidos e bem organizados, convictos sobre o papel que estavam exercendo. Também estiveram presentes a Associação das Marisqueiras de Acaú, as colônias de pescadores do litoral norte de Pernambuco, o CPP, a Assembléia Legislativa de Pernambuco, os técnicos do IBAMAPB e PE, CNPT, Fundação Nacional do Índio, e representantes do setor sucroalcooleiro do Estado de Pernambuco.

A particularidade desta consulta se deveu à presença e atuação dos empresários e advogados que representaram o setor sucroalcooleiro. Ao se confrontarem com a possibilidade de que a Resex pudesse trazer a efetiva regulamentação de suas atividades econômicas, exigiram a garantia de que a zona de amortecimento não atingisse suas terras. A solicitação foi indeferida pela equipe técnica, visto que a definição da zona de amortecimento era uma etapa posterior baseada em estudos e análises técnicas. A oportunidade gerada pela consulta estimulou comunitários e empresários a refletir sobre os limites para a exploração de um ambiente direcionado a atender interesses tão distintos.

Embora o discurso dos diferentes grupos estivesse passando por um processo de amadurecimento, foi possível identificar as preocupações comuns a qualquer uma das comunidades envolvidas na Resex e que persistiram em todas as fases de criação da UC: usineiros (envolvendo os canaviais e indústrias de beneficiamento da cana), fábrica de cimento na margem paraibana do estuário, viveiros de camarão, turismo desordenado, delimitação da zona de amortecimento, assistência técnica para a gestão da resex e disponibilização de recursos financeiros. 


\section{O DECRETO FORMALIZA A CRIAÇÃO DA RESEX ACAÚ-GOIANA}

Ao cumprir todas as etapas burocráticas exigidas por lei, é decretada a existência jurídica da Reserva Extrativista Acaú-Goiana em 26 de setembro de 2007. Com uma área aproximada de 6.700 ha, a Resex tem seus limites definidos entre o litoral norte de Pernambuco e o litoral sul da Paraíba, sendo o estuário dos rios Goiana e Megaó o protagonista desta UC, conforme apresenta a Figura 1:
Estiveram presentes aproximadamente 50 pessoas dentre marisqueiras, pescadores e representantes da Associação das Marisqueiras de Acaú, da Colônia de Pescadores de Acaú, Presidente da Colônia de Pescadores de Pitimbú, da Associação dos Produtores de Alga da Paraíba, da Colônia de Pescadores de Ponta de Pedras, da Articulação Estadual das Mulheres Pescadoras, Colônia de Pescadores de Atapúz, Colônia de Pescadores do Baldo do Rio, Colônia de Pescadores de Tejucupapo, do Governo do Estado da Paraíba, do IBAMA/PB.

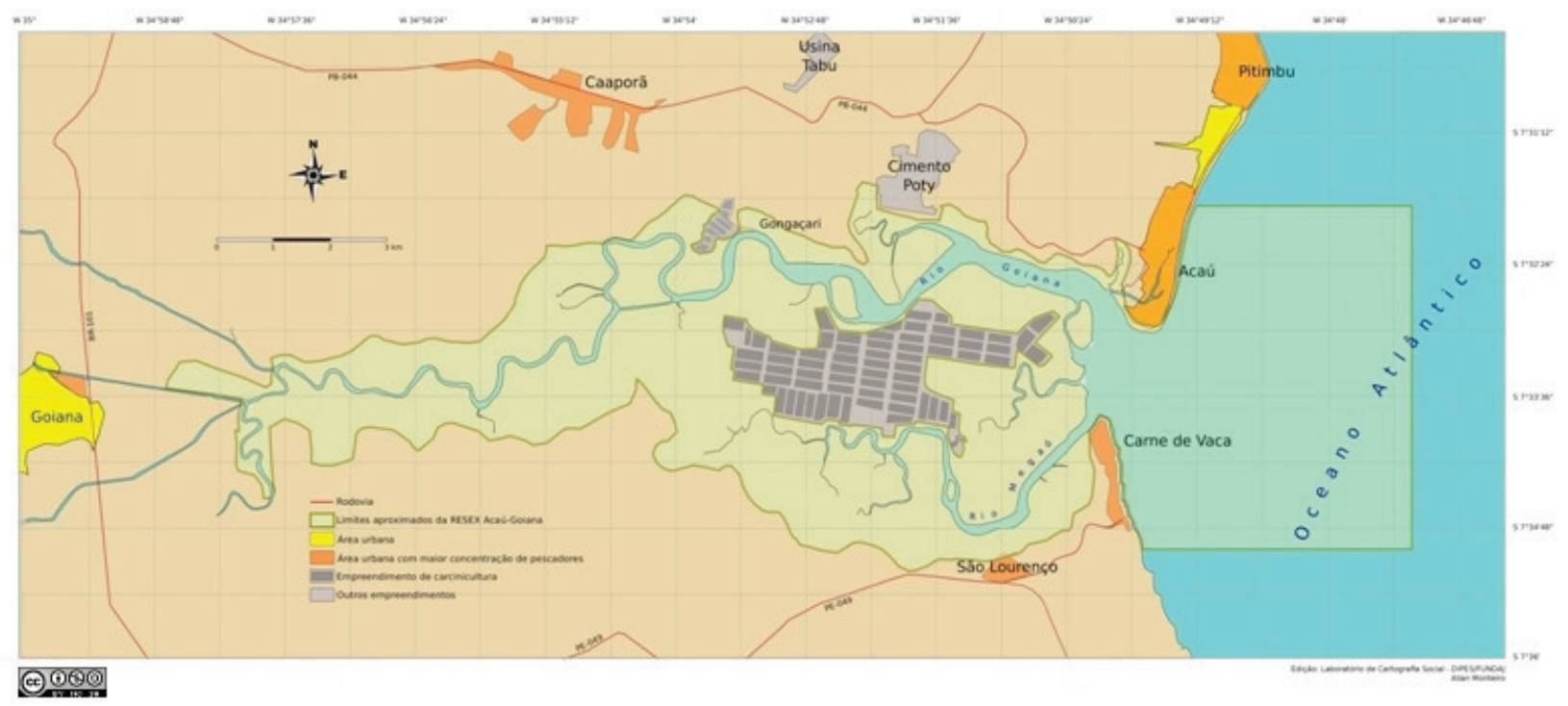

Figura 1: Mapa de Localização da Reserva Extrativista Acaú-Goiana.

Fonte: Mapa produzido por Allan Monteiro para o projeto "Reservas Extrativistas e pesca artesanal: etnografia do campo socioambiental em Pernambuco" (Fundaj/Facepe).

Se considerarmos a época na qual se iniciaram as primeiras discussões acerca da proteção da área do estuário, passaram-se oito anos para que as comunidades pudessem solenizar a existência formal da Reserva Extrativista Acaú-Goiana.

Após o decreto, o IBAMA/PB organizou uma reunião juntamente com as lideranças comunitárias da PB e de PE para oficializar a chegada da Resex em Acaú. Contudo, a reunião havia sido programada para ocorrer ao mesmo tempo em que se realizava um ato público do Governo do Estado da Paraíba e a ocorrência da maré baixa, que por si convoca as pescadoras ao trabalho. Essa soma de fatores provocou uma evidente evasão na reunião.
As líderes pescadoras se destacaram especialmente. Atentas à nova etapa da Resex, as líderes da Associação das Marisqueiras e da Colônia de Pescadores de Baldo do Rio e de Ponta de Pedras estabeleceram um consenso sobre o discurso que seria apresentado naquela reunião. As lideranças enfatizaram a 'maternidade' da resex, em contraposição aos "pais da reserva" que surgiram após o decreto, tal como políticos e/ou líderes que passaram a se posicionar como os grandes apoiadores do processo e responsáveis por seu êxito.

As lideranças se apropriaram da reunião e afirmaram as prioridades que deveriam ser tomadas a partir daquela etapa, como a regularização fundiária, a formação do Conselho Deliberativo, as linhas de 
financiamento, a união interna para a comunidade pesqueira, e o defeso.

\section{A FASE DO PÓS-CRIAÇ̃̃O}

Durante toda a análise do processo de criação da Resex Acaú-Goiana se verificou que as líderes comunitárias se destacaram por sua atuação constante para efetivar a UC e não permitir que a luta perecesse. Demonstraram uma grande capacidade de mobilização da comunidade pesqueira, além de terem desempenhado a função de interlocutoras entre esta comunidade e os órgãos técnicos, tornando o processo mais legítimo.

Ao mesmo tempo em que há uma força inegável das representantes, os representados ainda estão avançando na direção de um grupo uníssono e consciente da nova etapa da gestão do estuário. Por exemplo, todas as comunidades mantêm as mesmas lideranças. Não há o surgimento de novos comunitários interessados em articular as causas locais,
Vaca (PE). Os dados quantitativos foram analisados de forma descritiva e com a utilização do programa Statistic 7.

Os resultados apontam que $80 \%$ das marisqueiras em Acaú e 67\% em Carne de Vaca afirmaram conhecer sobre a existência da Resex, conseqüência direta do nível de participação nos espaços públicos que em Acaú chegou a 73\% das entrevistadas enquanto em Carne de Vaca atingiu 40\%. São números favoráveis que assinalam o interesse dessas mulheres pelo tema, porém não podem ser interpretados de forma dissociada dos diversos fatores que limitam o papel político da mulher.

Outras características podem ser apontadas para o quadro da participação das marisqueiras, como a falta de compreensão sobre o tema 'reserva extrativista' e a descrença em uma política denominada 'ambiental'. As incertezas começam no próprio ponto de partida, a definição do que seria reserva extrativista, como pode ser visto a seguir na Tabela 1:

\begin{tabular}{|c|c|c|c|c|c|c|}
\hline & $\begin{array}{c}\text { Área } \\
\text { Zoneada(\%) }\end{array}$ & $\begin{array}{c}\text { Área protegida } \\
\text { para conservação(\%) }\end{array}$ & $\begin{array}{c}\text { Área com } \\
\text { proibições de } \\
\text { algumas atividades } \\
(\%)\end{array}$ & Não compreendeu(\%) & $\begin{array}{c}\text { Não } \\
\text { opinou(\%) }\end{array}$ & Total $(\%)$ \\
\hline Acaú & 10,00 & 16,50 & --- & 16,50 & 7,00 & 50 \\
\hline Carne de vaca & 6,50 & 3,50 & 3,50 & 20,00 & 16,50 & 50 \\
\hline Total & 16,50 & 20,00 & 3,50 & 36,50 & 23,50 & 100 \\
\hline
\end{tabular}

Tabela 1: Compreensão das marisqueiras sobre o tema reserva extrativista

Fonte: Pesquisa direta. Abril, 2008

principalmente no caso das marisqueiras que, apesar de uma participação considerável nas reuniões da Resex, enfrentam diversas limitações sociais e laborais para atuar nos espaços decisórios em condições reais de participação ativa, sejam elas a responsabilidade pela unidade familiar ou a divisão sexual do trabalho (SARACENO, 1995; AGARWAL, 2001; ARAÚJO, 2001; TABAK, 2002; MORAES, 2003).

Com o intuito de analisar a fase da pós-criação da Resex junto à população de marisqueiras, foram realizadas entrevistas entre março e abril de 2008 com uma amostra representativa de 30 marisqueiras em ambas as comunidades de Acaú (PB) e Carne de
Mesmo as lideranças a frente de todo o processo enfrentam algumas incertezas, visto que são muitos os interesses econômicos pela área, permanecendo em determinados momentos uma atmosfera de insegurança e descrédito. Restam dúvidas quanto à funcionalidade e eficácia da Resex e inclusive sobre a real garantia dos direitos da comunidade pesqueira.

As marisqueiras enfrentam ainda outros desafios, pois a maioria não sabe como participar nos espaços públicos decisórios da Resex computando $67 \%$ das entrevistadas em Acaú e 87\% em Carne de Vaca. Tampouco conhecem sobre direitos e deveres que podem ser gerados a partir desta etapa, o que 
representa $80 \%$ das entrevistadas em Acaú e 93\% em Carne de Vaca.

\section{O QUE SE PODE ESPERAR PARA A GESTÃO DA RESEX}

Considerando o cenário geral da pesca artesanal na área da Resex Acaú-Goiana, as mulheres vêm se afirmando como parte da comunidade pesqueira. Inegavelmente elas predominam na atividade da temporânea de participação das mulheres nos espaços decisórios tem adentrado nas comunidades pesqueiras, antes espaços predominantemente masculinos.

Reforçando as expectativas para a Resex, técnicos, lideranças comunitárias e marisqueiras entrevistadas determinaram que tipo de mudança traria um diferencial para a comunidade e para o grupo das marisqueiras, contribuindo de forma efetiva com as fases de implantação e futura gestão da área, conforme demonstra o Quadro 3.

\begin{tabular}{|c|c|c|}
\hline & $\begin{array}{l}\text { Expectativas para } \\
\text { a comunidade }\end{array}$ & $\begin{array}{c}\text { Expectativas para } \\
\text { as marisqueiras }\end{array}$ \\
\hline Técnicos & $\begin{array}{l}\text { Protagonismo e mobilização da comunidade pesqueira; } \\
\text { Mudança de pensamento e postura que chame pra si a } \\
\text { responsabilidade da Resex; } \\
\text { Zoneamento e plano de manejo da área; } \\
\text { Unificar resultados de diversas pesquisas realizadas na } \\
\text { área e socializar com a comunidade; } \\
\text { A compensação ambiental oriunda dos empreendimentos } \\
\text { localizados no entorno da Resex; } \\
\text { Reunir diversos pólos de interesses em uma mesma mesa } \\
\text { de discussão. }\end{array}$ & $\begin{array}{l}\text { Empoderamento e auto-estima; } \\
\text { Aporte financeiro para fomentar a geração de renda; } \\
\text { Capacitar as marisqueiras para aproveitar de forma adequada } \\
\text { os empreendimentos turísticos que se instalarão no entorno da } \\
\text { Resex; } \\
\text { Aperfeiçoar as técnicas de pesca, melhorar os apetrechos e a } \\
\text { qualidade de vida em geral; } \\
\text { Estimular o associativismo; } \\
\text { Cooperativismo e ações, como a cozinha comunitária. }\end{array}$ \\
\hline Líderes & $\begin{array}{l}\text { Oportunidade de decidir sobre o destino da área; } \\
\text { Aumento da produção pesqueira; } \\
\text { Punição para a degradação ambiental provocada pelas } \\
\text { atividades econômicas do entorno da área; } \\
\text { Garantir o território da comunidade pesqueira; } \\
\text { Fortalecimento da luta em defesa do meio ambiente } \\
\text { (natural e do trabalho); } \\
\text { Consciência para exercer a pesca artesanal de forma } \\
\text { a cumprir todas as determinações legais, inclusive } \\
\text { fiscalizando as ações da própria comunidade pesqueira; } \\
\text { Acesso amplo à informação. }\end{array}$ & $\begin{array}{l}\text { Higienização do marisco utilizando outros equipamentos, como } \\
\text { uma "despolpadeira"; } \\
\text { Manter a forma tradicional da coleta nas croas, porém com } \\
\text { segurança do trabalho; } \\
\text { Buscar fonte alternativa para o uso da lenha no cozimento dos } \\
\text { mariscos; } \\
\text { Ampliar por meio de ações educativas o manejo adequado dos } \\
\text { mariscos; } \\
\text { O selo verde para os produtos da Resex, resignificando o } \\
\text { trabalho das marisqueiras. }\end{array}$ \\
\hline Marisqueiras & $\begin{array}{l}\text { As entrevistadas confiam que a Resex pode trazer } \\
\text { melhoria na vida da população, porém não souberam } \\
\text { precisar que tipo de melhorias. }\end{array}$ & $\begin{array}{l}\text { Defeso do marisco; } \\
\text { Reconhecimento da profissão perante os órgãos públicos e à própria } \\
\text { comunidade; } \\
\text { Capacitação e geração de emprego e renda para que as mulheres } \\
\text { tenham alternativas de trabalho; } \\
\text { Reuniões informativas sobre os direitos das marisqueiras; } \\
\text { Espaços comuns para realizar as etapas da mariscagem; } \\
\text { Benefícios para a cadeia produtiva do marisco. }\end{array}$ \\
\hline
\end{tabular}

Quadro 3: Expectativas para as próximas etapas da Resex Acaú-Goiana

Fonte: Pesquisa direta. Abril, 2008

mariscagem, poucos homens se envolvem em todas as etapas que compõe este trabalho. Além de estarem nos bancos de marisco, mesmo com todas as variáveis contra, são elas que reforçam os espaços públicos decisórios.

Ressalta-se que nem sempre as marisqueiras se posicionam nas reuniões formais, o que não significa que estão deixando de tecer uma rede interna de informações e passando adiante a percepção de que o ambiente estuarino, incluindo o mangue, sustenta seu trabalho e sua vida. Toda essa conjuntura con-

\section{CONCLUSÃO}

Instaurar as práticas participativas na esfera ambiental exige mais do que a normatização de princípios e preceitos já reconhecidos, significa restaurar uma cultura de promoção da autonomia dos atores sociais que se distancie do assistencialismo e autoritarismo.

E pensando em processos participativos e autonomia política não se pode ignorar que espaços decisórios sem equidade correspondem apenas aos 
interesses de uma metade da sociedade. As mulheres levaram um longo período até que pudessem participar de diferentes contextos sociais. As mulheres pescadoras, por exemplo, tardaram para conseguir afirmar que o mar e os rios também são seus espaços e que neles empenham o importante papel de gestoras ambientais.

Ainda que se apresente este quadro, as marisqueiras do estuário dos rios Goiana e Megaó não se omitiram quando olharam para o ambiente e se depararam com a destruição do seu oikos e da sua dignidade, motivando-as a exercer um papel fundamental: diagnosticar os problemas ambientais pelo qual passava o estuário e fomentar a discussão.

As marisqueiras legitimaram o processo de criação da Resex Acaú-Goiana, e isso pode ser afirmado pela constante presença dessas atrizes nas diversas reuniões que constituíram a resex, bem como pela participação valiosa de suas lideranças.

A iniciativa da Resex surgiu da base, da inquietação de marisqueiras que conviviam diariamente com o rio, o mangue e as croas, observando cada alteração que ocorria no ambiente. E estas mudanças passaram a atingir o principal recurso que sustentava seu trabalho, o marisco. Considerando que mais da metade das marisqueiras sustentam suas famílias, mesmo com remunerações baixas, o desequilíbrio no ambiente trouxe ainda o desequilíbrio doméstico, despertando estas mulheres para exercer sua cidadania ativa.

Apesar das marisqueiras não terem iniciado esse processo com a compreensão dos fatos que pede a conveniência técnica, o papel de cidadãs ativas não pode ser invalidado, pois a mobilização social, essencial nos processos participativos, também se sustenta na rede formada por mulheres que desempenham a função fundamental de articuladoras, como no caso das lideranças que representaram o posicionamento da comunidade pesqueira em todas as instâncias.

A questão é reconhecer as contribuições que este grupo social trouxe ao processo de criação da Resex Acaú-Goiana: 1. A começar pela iniciativa, que partiu das marisqueiras; 2 . O interesse no assunto, mesmo com condições socioculturais e econômicas desfavoráveis a elas; 3 . A coragem de denunciar os gigantes do setor produtivo da região que resistem em cumprir a legislação ambiental; 4. E ainda sua presença, que caracterizou a diversidade de atores sociais nos espaços decisórios.

Se houve uma falha, esta pode ser atribuída ao fato de que as intervenções nestes espaços públicos decisórios se concentraram em grande parte nas mãos das lideranças locais. Contudo, esta falha deve ser compartilhada com os órgãos ambientais, pois, como condutores do processo, tinham o dever de primar por medidas que viabilizassem a atuação das mulheres adotando metodologias que proporcionassem a participação equitativa nos espaços decisórios.

Quanto à Resex Acaú-Goiana, ficou evidente sua relevância, em primeiro lugar porque o ambiente ganhou importantes parceiros para a sua conservação. A decisão da comunidade local de proteger a área foi bastante adequada para o contexto da crescente exploração desordenada que vinha assolando o estuário dos rios Goiana e Megaó. Além deste fator, ressalta-se o cenário de participação política que a Resex trouxe à comunidade, permitindo que atores sociais e interesses tão divergentes tivessem a oportunidade de dialogar. Por último, o fato de que a resex inseriu as mulheres nas esferas de decisão sobre o próprio ambiente que tanto contribuem para conservar.

Cabe concluir que as marisqueiras conquistaram, com a criação desta área protegida, um importante instrumento de empoderamento e um espaço que fortalece o debate, dando voz às ações ambientais rotineiramente desempenhadas por estas gestoras do meio ambiente.

\section{AGRADECIMENTOS}

As autoras agradecem às comunidades de Acaú (PB) e Carne de Vaca (PE), ao Programa Regional de Pós-Graduação em Desenvolvimento e Meio Ambiente, Sub-Programa UFPB/UEPB e ao CNPq pela bolsa de mestrado concedida a Amanda B. M. Fadigas.

\section{REFERÊNCIAS}

AGARWAL, B. Participatory exclusions, community forestry, and gender: an analysis for South Asia and a conceptual framework. World Development. Elsevier 
Science. v. 29, n. 10, 2001. 1623-1648 p.

AGUILAR, L.; CASTAÑEDA, I. Sobre marinos, marinas, mares y mareas: perspectivas de género en zonas marino-costeras. 1. ed. San José: UICN, 2000.

ALEXANDRE, A. A política que se aprende: Avaliando o processo de implementação das reservas extrativistas no Brasil à luz do ideário da etnoconservação. Cadernos de Pesquisa Interdisciplinar em Ciências Humanas. Programa de Pós-Graduação Interdisciplinar em Ciências Humanas/Doutorado, 2002.

ANTUNES, P. B. Direito Ambiental. 8. ed. Rio de Janeiro: Lúmen Júris, 2005.

ARAÚJO, C. Construindo novas estratégias, buscando novos espaços políticos - as mulheres e as demandas por presença. Mulher, Gênero e Sociedade. Rio de Janeiro: Relume Dumará, 2001. 82-98 p.

BAQUERO, M. Cultura política participativa e desconsolidação democrática: reflexões sobre o Brasil contemporâneo. São Paulo: São Paulo em Perspectiva. v. 15, n. $4,2001$.

BRASIL. Lei $n$. 9.985, de 18 de julho de 2000 que institui o Sistema Nacional de Unidade de Conservação. Brasília, 2000.

BRASIL. Decreto n. 4.340, de 22 de agosto de 2002, que regulamenta artigos da Lei n. 9.985, de 18 de julho de 2000, que dispõe sobre o Sistema Nacional de Unidades de Conservação da Natureza - SNUC. Brasília, 2002.

BRASIL. Instrução Normativa $n$. 03, de 18 de setembro de 2007 que disciplina as diretrizes, normas e procedimentos para a criação de Unidades de Conservação Federal das Categorias de Reserva Extrativistas e Reserva de Desenvolvimento Sustentável. Brasília, 2007.

DAGNINO, E. Sociedade civil, participação e cidadania: de que estamos falando? In: MATO, D. (Coord.), Políticas de ciudadanía y sociedad civil en tiempos de globalización. Caracas: Facultad de Ciencias Económicas y Sociales, Universidad Central de Venezuela, 2004. 95-110 p.

DIAS, T.; ROSA. R.; DAMASCENO, L. Aspectos socioeconômicos, percepção ambiental e perspectivas das mulheres marisqueiras da Reserva de Desenvolvimento Sustentável Ponta do Tubarão (Rio Grande do Norte, Brasil). Gaia Scientia. João Pessoa: Editora UFPB, v. 1, n. 1, p. 25-35, 2007.

DI CIOMMO, R. C. Pescadoras e Pescadores: a questão da eqüidade de gênero em uma reserva extrativista marinha. Ambiente e Sociedade. Campinas. v. X, p. 151-163, 2007.

DIEGUES, A. O mito da natureza intocada. São Paulo: Hucitec, Núcleo de Apoio à Pesquisa sobre Populações Humanas e Áreas Úmidas Brasileiras, USP, 2000.

FADIGAS, A.; GARCIA, L. O protagonismo das marisqueiras na criação da Reserva Extrativista Acaú-Goiana. In: $26^{a}$ REUNIÃO BRASILEIRA DE ANTROPOLOGIA-DESIGUALDADE NADIVERSIDADE, Porto Seguro, Anais... Porto Seguro, 2008.

FADIGAS, A.; GARCIA, L.; HERNANDEZ, M. As contribuições das marisqueiras para a gestão socioambiental em Resex marinhas. In: SEMINÁRIO INTERNACIONAL FAZENDO GÊNERO 8: CORPO, VIOLÊNCIA E PODER. Florianópolis, Anais... Florianópolis, 2008.

GARCIA, L. Impacto da Via Expressa Sul sobre a Reserva Extrativista Marinha de Pirajubaé/RESEX, 1999.

MORAES, M. L. Cidadania no feminino. In: PINSKY, J.; PINSKY, C. (Org.), História da cidadania. São Paulo: Contexto, 2003.

PRADO, R. "Depois que entrou o Imbamba": percepção de questões ambientais na ilha grande. In: XXII REUNIÃO BRASILEIRA DE ANTROPOLOGIA, Brasília. Anais... Brasília, 2000. 
SANTILLI, J. Socioambientalismo e novos direitos. São Paulo: Peirópolis; Instituto Internacional de Educação no Brasil; Instituto Socioambiental, 2005.

SARACENO, C. A dependência construída e a interdependência negada. Estruturas de gênero da cidadania. In: BONACHHI, G.; GROPPI, A. (Org). O dilema da Cidadania. Unesp, São Paulo, 1995, p. 205-234.

SIMONIAN, L. Pescadoras de camarão: gênero, mobilização e sustentabilidade na Ilha Trambioca, Barcarena, Pará. Boletim do Museu Paraense Emílio Goeldi, Belém, v. 1, n. 2, p. 35-52, 2006.

STADTLER, H.; CARNEIRO, S. Pescadoras: gênero e classe numa mesma articulação. In: SEMINÁRIO INTERNACIONAL FAZENDO GÊNERO: Seminário Internacional Fazendo Gênero 7 - Gênero e Preconceitos, 2006, Florianópolis. Anais... Florianópolis, UFSC, 2006.

TABAK, F. Mulheres Públicas: participação política e poder. Rio de Janeiro: Letra Capital, 2002. 